Research Paper

\title{
Optical dating of clastic deposits generated by an extreme marine coastal flood: The 1755 tsunami deposits in the Algarve (Portugal)
}

\author{
P.P. Cunha ${ }^{a, *}$, J.P. Buylaert ${ }^{b}$, A.S. Murray ${ }^{b}$, C. Andrade ${ }^{c}$, M.C. Freitas ${ }^{c}$, F. Fatela ${ }^{c}$, J.M. Munhá $^{c}$, \\ A.A. Martins ${ }^{\mathrm{d}}$, S. Sugisaki $^{\mathrm{e}}$ \\ ${ }^{a}$ Department of Earth Sciences, Marine and Environmental Research Centre, University of Coimbra, Portugal \\ ${ }^{\mathrm{b}}$ Nordic Laboratory for Luminescence Dating, Department of Earth Sciences, Aarhus University, Risø DTU, DK 4000, Denmark \\ ${ }^{\mathrm{c}}$ Departamento de Geologia \&' Centro de Geologia, Faculdade de Ciências da Universidade de Lisboa, Portugal \\ ${ }^{\mathrm{d}}$ Centro de Geofisica, Department of Earth Sciences, University of Évora, Portugal \\ ${ }^{\mathrm{e}}$ Department of Polar Science, School of multi-disciplinary Sciences, The Graduate University for Advanced Studies, c/o National Institute of Polar Science, Japan
}

\section{A R T I C L E I N F O}

\section{Article history:}

Received 20 October 2008

Received in revised form

4 September 2009

Accepted 8 September 2009

Available online 13 September 2009

\section{Keywords:}

Quartz

OSL dating

Tsunami deposits

Lisbon earthquake

Algarve

Portugal

Residual dose

\begin{abstract}
A B S T R A C T
Identification of past tsunamis is important for risk assessment and management of coastal areas. Obtaining accurate and precise ages of sediments originating from such extreme marine coastal floods is crucial for a reliable estimation of the recurrence interval of these often devastating events. We present here the results of quartz optical dating and ${ }^{14} \mathrm{C}$ dating of two sites (Boca do Rio and Martinhal) on the Algarve coast (southern Portugal). These sites contain deposits of the great tsunami of November 1,1755 . The sections were described using sedimentological techniques; at both sites tsunami-laid sands and gravels were identified, intercalated between estuarine muds. Quartz luminescence ages from these sedimentary successions were derived using standard SAR-OSL dating using multi-grain sub-samples. A multiple sampling strategy was employed with several samples taken from the AD 1755 tsunami deposit and from the sediments bracketing the tsunami layer. Our SAR-OSL protocol was shown to be appropriate using dose recovery measurements (measured/given dose ratio of $1.004 \pm 0.007, n=165$ ). The several OSL ages from the 1755 tsunamigenic deposits are internally reproducible but yield age overestimates of between 20 and 125\% (60-310 years respectively); this is in agreement with values reported in the literature for similar deposits. The age overestimation of the tsunami-laid sands is presumably due to the rapid erosion and deposition of older sediments, with insufficient light exposure for complete bleaching during the tsunami event itself. The absence of significant bleaching during the tsunami is also suggested by the shape of the dose distributions based on sub-samples made up of only about 100 grains. Analysis of the distributions with the minimum-age model seems to yield the expected age for two of the three distributions. It is important to note that age offsets of a few tens of years to a few hundred years rapidly become insignificant when dating older ( $>1$ to few ka) tsunami layers.
\end{abstract}

(c) 2009 Elsevier B.V. All rights reserved.

\section{Introduction}

Tsunamis can cause severe coastal erosion, but also transport and deposit different sized particles, ranging from clay to boulders, inland (Dawson, 1994). Establishing a chronology of tsunami events preserved in the geological record (e.g. Morales et al., 2008) is important for the estimation of the average recurrence interval and time dispersion of extreme marine coastal floods and in the assessment of seismic hazards of a region. Luminescence dating methods have previously been applied to tsunami deposits using thermoluminescence (TL; e.g. Bryant et al., 1996), infrared

\footnotetext{
* Corresponding author. Tel.: +351 239860 541; fax: +351 239860501.

E-mail address: pcunha@dct.uc.pt (P.P. Cunha).
}

stimulated luminescence (IRSL; e.g. Huntley and Clague, 1996; Ollerhead et al., 2001) and optically stimulated luminescence (OSL; e.g. Banerjee et al., 2001).

The earthquake of 1st November 1755 was of high magnitude (8.5) and generated a tsunami (Baptista et al., 1998a,b) that flooded the Algarve coast (southern Portugal) and deposited sediments in the lowlands of Boca do Rio (BDR) and Martinhal (MRT). At Boca do Rio the ages reported for those sediments in several independent studies are quite diverse (e.g. Dawson et al., 1995; Hindson and Andrade, 1999; Hindson et al., 1999; Allen, 2003). At Martinhal, the ages reported by Kortekaas and Dawson (2007) were found to be problematic because they are not in stratigraphic order, leading the authors to state that in their study luminescence dating was not a reliable method to date the 1755 tsunami layer. 
In this paper, we test both spatially and stratigraphically the application of standard large aliquot quartz SAR-OSL dating to both the 1755 tsunami deposits and to the bracketing sediment units at the Boca do Rio and Martinhal sites. The twenty-one OSL and four ${ }^{14} \mathrm{C}$ ages from our study are compared with previously published luminescence and ${ }^{14} \mathrm{C}$ ages for the same sites and with the known age of the deposit (250 years). The purpose of this work is to test the accuracy of standard large aliquot quartz SAR-OSL for dating the 1755 tsunami layer on the Portuguese coast, and by implication, for dating older deposits of similar origins.

\section{Sites and sampling strategy}

The Boca do Rio and Martinhal wetlands are separated from the sea by sand-shingle beach barriers, which confine alluvial plains that dry out during the summer but are periodically flooded by freshwater during winter.

An eyewitness reported the 1755 event as having occurred on a bright sunny morning during flood tide, producing on the Algarve coast a run-up that was estimated as ca. 11-15 m. According to historical records, the tsunami flooded ca. $1 \mathrm{~km}$ inland at Boca do Rio (Fig. 1a). A tsunami-laid sand wedge, $<50 \mathrm{~cm}$-thick, containing shell fragments, cobbles and boulders with borings of marine endolithobionts represents the 1755 event at this location (Dawson et al., 1995; Silva et al., 1996). In our study two trenches were dug at BDR, a southern trench (BDR-ST) and a northern trench (BDR-NT), located $300 \mathrm{~m}$ and $600 \mathrm{~m}$ from the modern beach respectively (Fig. 1a). The tsunami sand was found at depths of $100-120 \mathrm{~cm}$ (BDR-NT) and 70-100 cm (BDR-ST), intercalated with estuarine muds that rest upon more open-marine sands. Three OSL samples were taken laterally several meters apart in the tsunami layer in the southern trench and four in the northern trench; OSL samples were also collected from the sediments above and below the tsunami layer. A schematic description of the stratigraphy and the OSL sample locations is given in Figs. 2 and 3.

The trench excavated at Martinhal (Fig. 1b), located close $(\sim 100 \mathrm{~m})$ to the sampling location of Kortekaas and Dawson (2007), showed a more diverse stratigraphy. Here, multiple shell-rich sand and gravel layers were identified within estuarine deposits, of which at least one, according to witness reports, should correspond to the 1755 event. The characteristics of the coarser sediments indicate a marine source (good sorting, high roundness of quartz grains, presence of marine bioclasts, etc.), consistent with having been deposited by an extreme marine coastal flood. We identify this layer with the 1755 tsunami deposit. Three OSL samples were taken in this marine layer and three in the silt and sand layers below (Fig. 4).

\section{Published absolute age information}

Following the first study of the upper Holocene at Boca do Rio by Andrade et al. (1994), Dawson et al. (1995) described in detail the lithostratigraphic units at a trench close to our BDR-ST. They characterized the units as follows from the surface to depth: unit A - dark red/brown silt that towards its base changes to an organic silty clay, up to $0.8 \mathrm{~m}$ thick; unit B - mainly medium sand but sometimes grading from very fine to coarse sand at its erosive base, containing marine macro- and micro-fossils, $0.1-0.4 \mathrm{~m}$ thick; unit C1 - brown organic clay-rich silt containing fossil stems and rootlets and occasional fragments of charcoal and shells, $0.1-1.0 \mathrm{~m}$ thick; unit C2 - brown/black and organic silty clay, 0.1-1.0 m thick; unit D1 - medium sand, 0.1-3.2 m thick; unit D2 - bioclastic gravel, $>0.5 \mathrm{~m}$ thick. For unit B, identified as the tsunami layer, a thermoluminescence age estimate of $260 \pm 60$ yrs (AD1734 \pm 60 ) was listed (no sample code was provided); radiocarbon dates (accelerator mass spectrometry - AMS) of units C1 and C2 yielded $1890 \pm 60$ yrs cal BP (Beta-68853) and $1210 \pm 60 \mathrm{yrs}$ cal BP (Beta-68854) (Dawson et al., 1995) (Fig. 2).

Hindson et al. (1999), in the same Boca do Rio area close to BDRST, provided detailed foraminifera and ostracod analyses, but also an OSL chronology (OSL ages before 1995, in years) based on seven samples collected from a trench: BDR-A (587 \pm 38$)$, BDR-B $(194 \pm 76)$, BDR-C1 $(1236 \pm 540)$, BDR-C2 (1363 \pm 420$),$ BDR-D1 $(1815 \pm 411)$, BDR-D2 (1944 \pm 280$)$ and BDR-D3 (2320 \pm 617$)$; samples BDR-D1, BDR-D2 and BDR-D3 were collected from the unit D1 defined by Dawson et al. (1995) and provided ages that are in stratigraphic order (Fig. 2). For units $A$ and $C$ the $4-11 \mu \mathrm{m}$ polymineral fraction was used and for units B and D the $180-225 \mu \mathrm{m}$ quartz fraction. Equivalent dose determination was done by the additive-dose method and a halogen light source; luminescence detection was in the UV through a U-340 filter pack. The dosimetry was based on on-site gamma spectrometry and thick source beta counting. An estimate of $5 \%$ was used for the water content, although the authors acknowledge that this may be too conservative for their environment.

Allen (2003) made a palaeoecological analysis of a $3 \mathrm{~m}$ core from the same lowland close to BDR-NT. Standard radiocarbon dates were determined for three organic silts (numbers in the sample code denote depth in $\mathrm{cm}$ ): $1062 \pm 150$ yrs cal BP - BDR135-138, $936 \pm 140$ yrs cal BP - BDR146-148, 1171 (1304-966) yrs cal BP BDR253-254; a shell hash, dated as 8955 (8994-8660) yrs cal BP BDR286-294, was rejected because it was considered to be not in situ. An AMS radiocarbon date on a shell yielded 1046, 1040, 974 (1061-935) yrs cal BP - BDR253-254 (Fig. 3).

For Martinhal, the published information is not easy to interpret because of the complex stratigraphy in the Martinhal lowland (spatially very variable), which does not allow us to reliably connect both stratigraphies. Furthermore, the OSL results presented by Kortekaas and Dawson (2007) were considered problematic by the authors (also no experimental details are given). Because of the difficulty of relating both studies, we restrict ourselves to reporting the OSL results of Kortekaas and Dawson which were obtained on the two samples taken in the layer identified by them as being deposited by the 1755 tsunami: one sample (MRT3) yields an of $3199 \pm 2008$ yrs whereas the other sample (MRT2) yields and age of $74 \pm 45$ yrs (Fig. 4).

\section{4. ${ }^{14} \mathrm{C}$ dating}

In our study, a radiocarbon age (Beta83686 - $2250 \pm 60$ yrs BP, 1515 yrs cal BP) was obtained on an endolithic shell extracted from a limestone boulder within the 1755 tsunami layer in a location near BDR-ST (Fig. 2).

From unit $\mathrm{C} 1$, at a depth of $1.96 \mathrm{~m}$ in a pit located close to BDRNT, three AMS radiocarbon results were obtained from the same estuarine mud sample: Beta241183 - $1400 \pm 40$ yrs BP (930 yrs cal BP) from a shell; Beta241186 - $1480 \pm 40$ yrs BP (1360 yrs cal BP) from particulate carbon; Beta241187 - $370 \pm 40$ yrs BP (470 yrs cal BP) from charcoal (Fig. 3).

\section{Luminescence dating}

\subsection{Sample preparation and measurement details}

Quartz grains in the range $180-250 \mu \mathrm{m}$ were extracted from the inner part of $30 \mathrm{~cm}$ long ( $7.5 \mathrm{~cm}$ diameter) PVC or stainless steel tubes using conventional sample preparation techniques (sieving, $10 \% \mathrm{HCl}, 10 \% \mathrm{H}_{2} \mathrm{O}_{2}, 40 \% \mathrm{HF}$ ). The grains were mounted on stainless steel discs using silicon spray. All measurements were made on large aliquots containing several thousands of grains, except where 

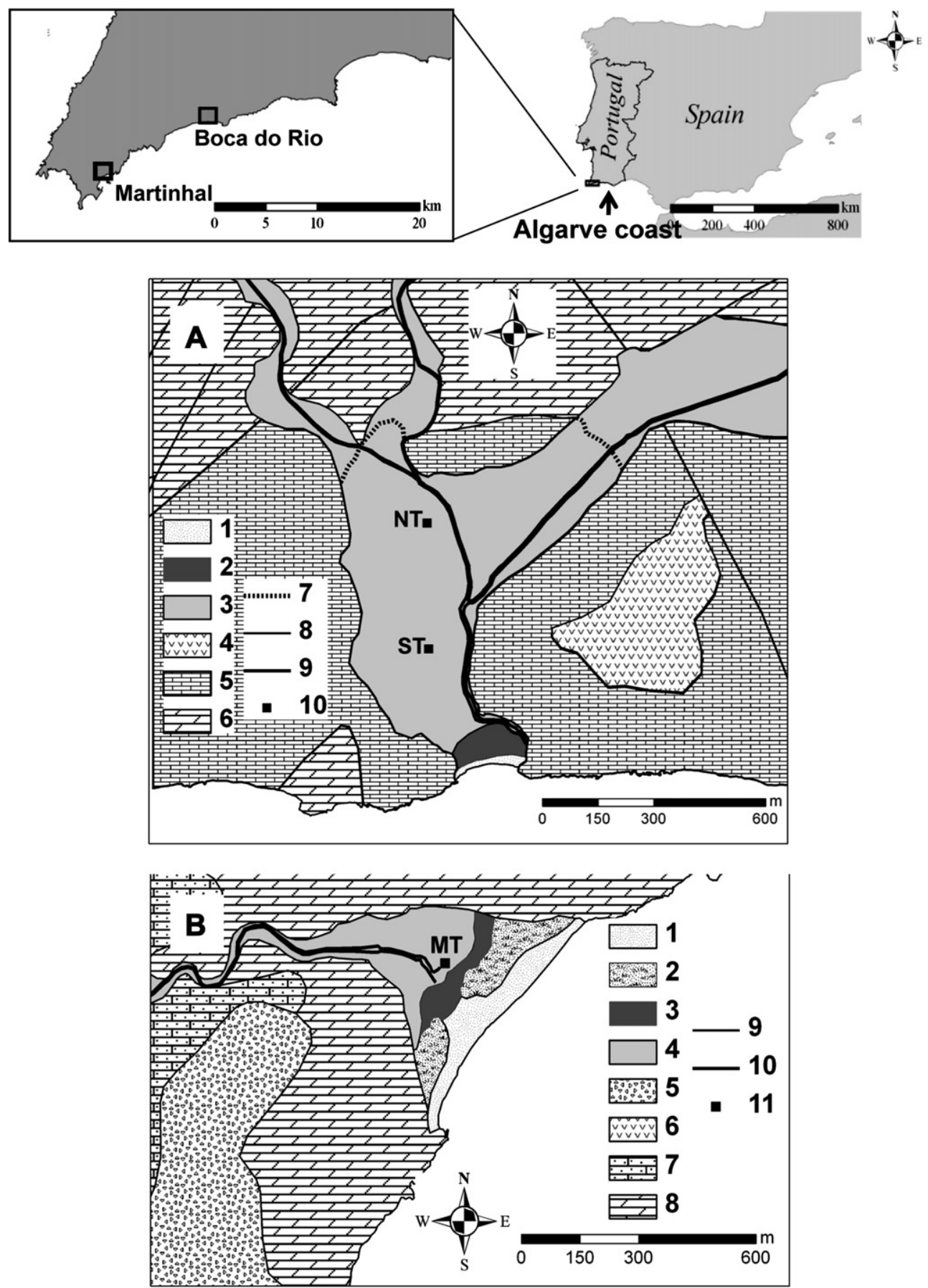

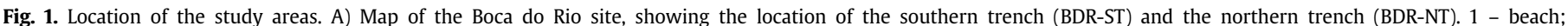

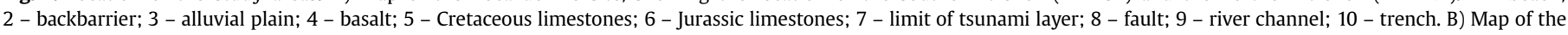

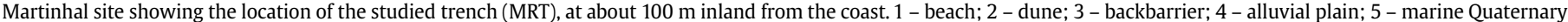
terrace; 6 - basalt; 7 - Miocene calcarenites; 8 - Jurassic limestones; 9 - fault; 10 - river channel; 11 - trench.

otherwise stated in the text. Measurements were made with a conventional Risø TL/OSL DA-15 and DA-20 systems equipped with an array of blue $\left(470 \mathrm{~nm}, \sim 50 \mathrm{~mW} \mathrm{~cm}^{-2}\right.$ ) and infrared (IR) LEDs $\left(870 \mathrm{~nm}, \sim 200 \mathrm{~mW} \mathrm{~cm}^{-2}\right.$ ) (Bøtter-Jensen et al., 2003). Luminescence was detected through $\sim 7 \mathrm{~mm}$ of U-340 filter. A SAR protocol (Murray and Wintle, 2000, 2003) using a fixed test dose of $\sim 1$ Gy and a high temperature clean-out ( $40 \mathrm{~s}$ blue light at $280^{\circ} \mathrm{C}$ ) after every SAR cycle was used to determine the $D_{\mathrm{e}}$ values of our samples (the preheat conditions are discussed later). The integral of the first $0.8 \mathrm{~s}$ of the stimulation curve was used for $D_{\mathrm{e}}$ determination, after subtracting the background signal derived from the $1.5-2.5 \mathrm{~s}$ integral. The purity of the quartz extracts was confirmed by the absence of an IRSL signal. Nevertheless an IR OSL depletion test (Duller, 2003) was carried out on every aliquot (aliquots with an IR OSL depletion ratio $<0.90$ were rejected from the analysis; less than 15 out of $>500$ measured aliquots needed rejection on the basis of this criterion). 


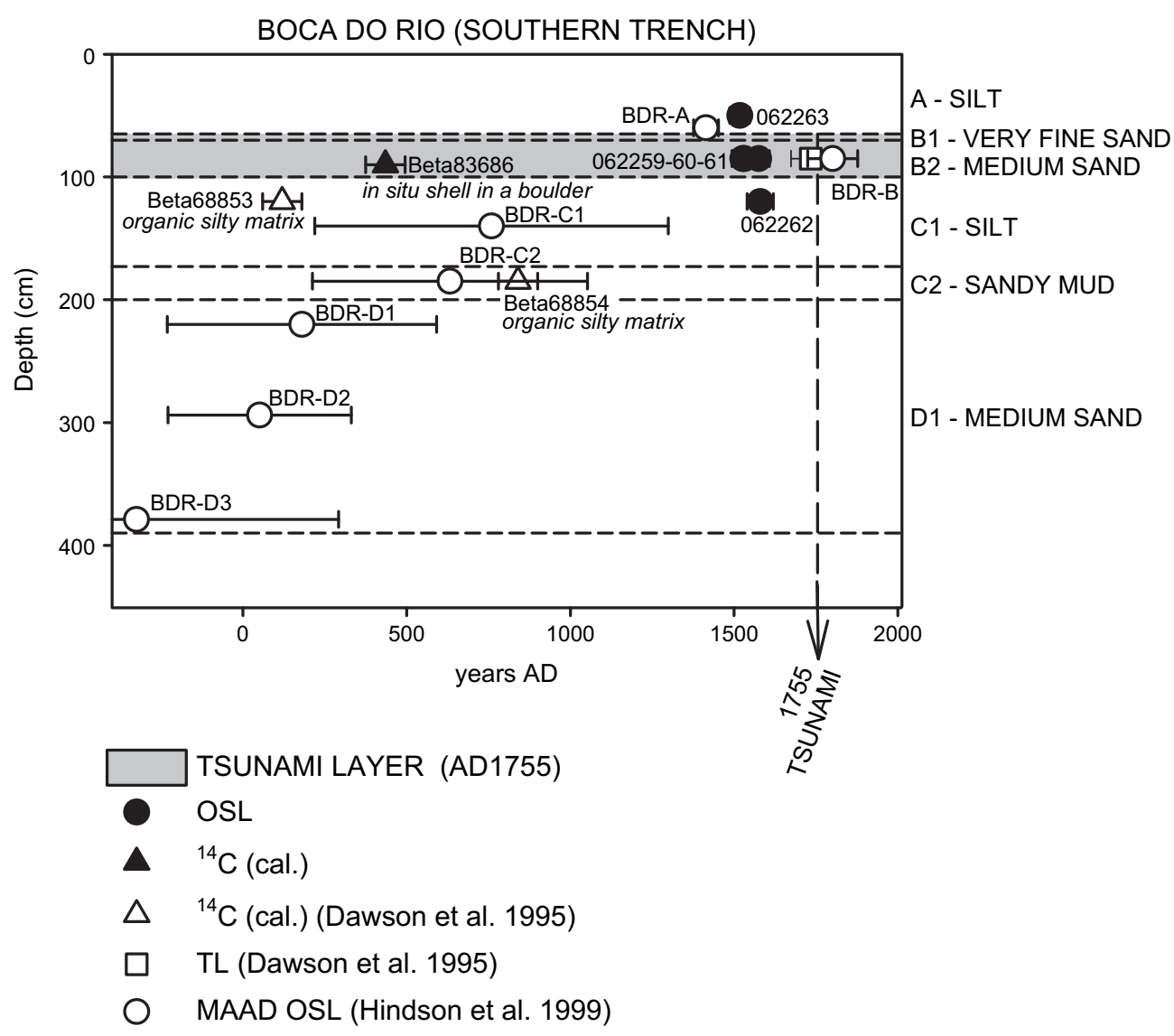

Fig. 2. Luminescence and radiocarbon ages against depth $(\mathrm{mm})$ for the Boca do Rio southern trench (BDR-ST).

\subsection{Luminescence characteristics}

Figures S1-3 present the luminescence characteristics of this material. Natural signals for all our samples lie in the linear region of the SAR growth curve (Fig. S1). The blue light stimulated signal is clearly dominated by a strong fast component (see inset Fig. S1). When dating such young samples with $D_{\mathrm{e}}$ values $<\sim 5 \mathrm{~Gy}$ it is important to check for the preheat dependence of the $D_{\mathrm{e}}$ (Madsen and Murray, 2009). Thus, thermal transfer and preheat plateau tests were carried out (Fig. S2a-c). In the thermal transfer test, aliquots were first bleached with blue LEDs ( 2 times $40 \mathrm{~s}$ at room temperature in the reader) and then measured in the usual manner. Thermal transfer is negligible below $\sim 200^{\circ} \mathrm{C}$ and then starts to increase with preheat temperature. There is no evidence for a systematic trend in $D_{\mathrm{e}}$ with preheat temperature (Fig. 2Sb). Recycling ratios are close to unity and recuperation (response to a zero dose in the SAR procedure) is negligible up to $\sim 280^{\circ} \mathrm{C}$. From all these data it is clear that preheat temperatures $\leq 200^{\circ} \mathrm{C}$ should be suitable. We finally checked whether a known dose given prior to any heating of the sample can be recovered in the laboratory (Murray and Wintle, 2003). Aliquots were first bleached twice with blue light at room temperature for $40 \mathrm{~s}$ and then given a beta dose approximately equal to the natural dose. This dose was then measured in the usual way, with a preheat of $200^{\circ} \mathrm{C}$ for $10 \mathrm{~s}$ and cut-heat to $180^{\circ} \mathrm{C}$. The results are shown as a histogram in Fig. S3. The mean measured to given dose ratio is $1.004 \pm 0.007(n=165)$. We conclude that we can accurately recover a given dose in the laboratory prior to any heat treatment. Based on these results, a preheat of $200{ }^{\circ} \mathrm{C}$ for $10 \mathrm{~s}$ and a cut-heat to $180^{\circ} \mathrm{C}$ were selected for all subsequent $D_{\mathrm{e}}$ measurements.

\subsection{Dosimetry}

The dose rates were derived from high-resolution laboratory gamma spectrometry (Murray et al., 1987). A contribution from cosmic rays was calculated, based on Prescott and Hutton (1994). The water content prevailing throughout the burial time was assumed to be $2 / 3$ of measured saturation water content; the trenches were dug in supra-tidal wetlands and at the time of collection the sample water contents were close to saturation due to a recent rain episode. For the thin tsunami sand layers (10$20 \mathrm{~cm}$ ) the gamma contribution to the total dose rate was evaluated for every sample using the model described in Appendix $\mathrm{H}$ from Aitken (1985). The derived dose rates lie in the range $0.8-2.4 \mathrm{~Gy} / \mathrm{ka}$ for the tsunami sands and 2.6-4.2 Gy/ka for the bracketing muds (Table S1). The luminescence ages are given in Table S1 and presented together with the other available age information in agedepth diagrams in Figs. 2-4 for the BDR-ST, BDR-NT and MRT trenches.

\section{Luminescence and radiocarbon chronologies}

In the BDR-ST (Fig. 2) the age for the OSL sample in unit A1 $(062263-\mathrm{AD} 1515 \pm 30)$ is older than the expected 250 years (AD1755); it is possible that the fluvial silt from unit A was not significantly bleached at deposition, as already suggested by Hindson et al. (1999; age for their corresponding sample BDR-A AD1408 \pm 38$)$. Our OSL ages for unit B (062259 - AD1525 \pm 34 ; 062260 - AD1531 $\pm 34 ; 062261-\mathrm{AD} 1575 \pm 33$;) are very reproducible but overestimate the 1755 event by $\sim 200$ years. The tsunami sands have a different source from the adjacent A1 


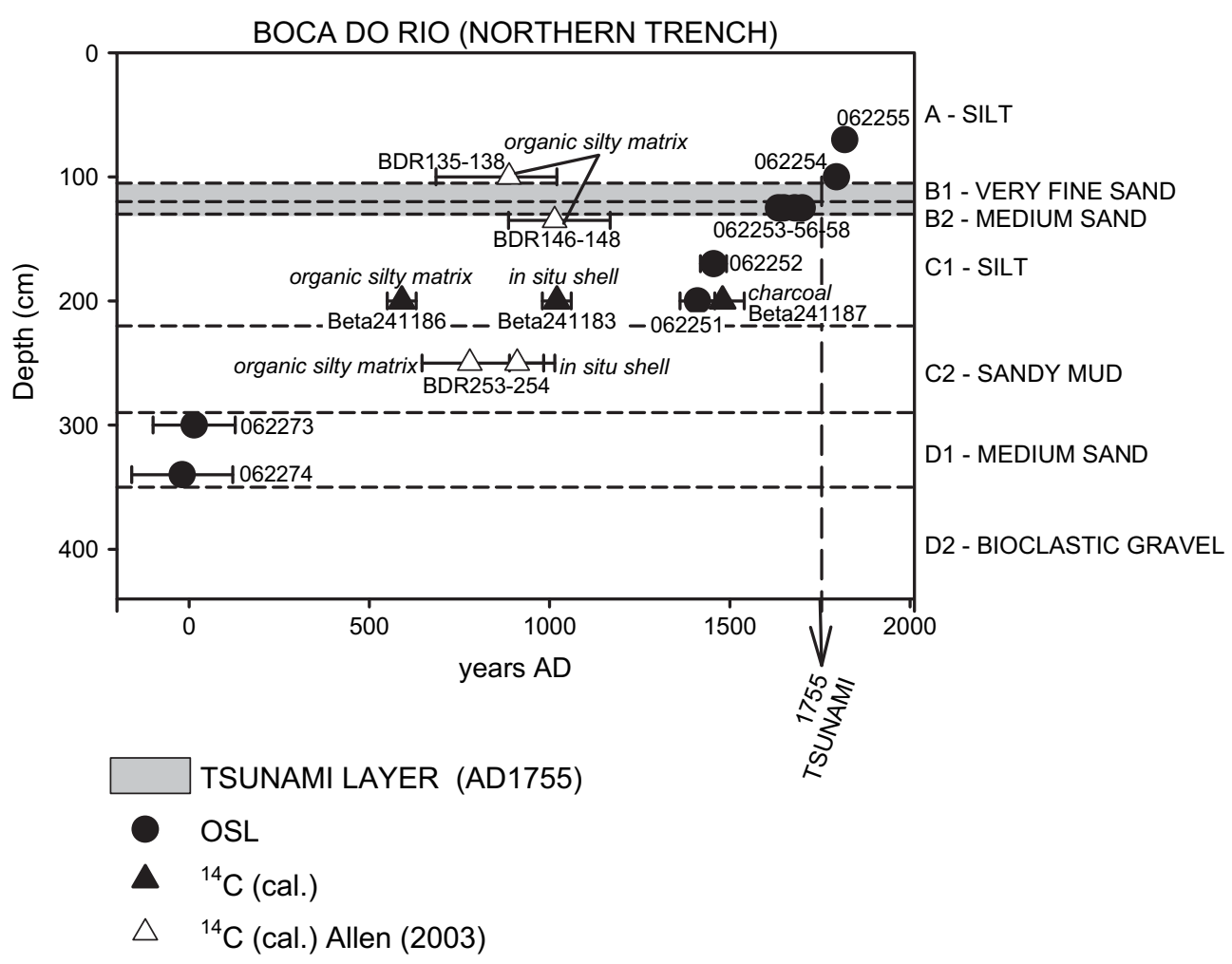

Fig. 3. Luminescence and radiocarbon ages plotted against depth ( $\mathrm{mm}$ ) for the Boca do Rio northern trench (BDR-NT).

$(062263-\mathrm{AD} 1515 \pm 30)$ and $\mathrm{C} 1$ units $(062262-\mathrm{AD} 1580 \pm 40)$ and thus the OSL age agreement between these units is regarded as coincidental. The apparent accuracy of the TL age (AD1734 \pm 69 ) from unit B reported by Dawson et al. (1995) is very surprising for a tsunami deposit; it would be expected that the TL technique would yield an age overestimation. The OSL age obtained by Hindson et al. (1999) for B unit is younger than our results and close to the expected age of 250 years. The other OSL ages they obtained in units C1 (BDR-C1 - AD759 \pm 540$), C 2$ (BDR-C2 - AD632 \pm 420$)$ and D1 (BDR-D1 - AD180 \pm 411, BDR-D2 - AD51 \pm 280 , BDR-D3 $\mathrm{BC} 325 \pm 617)$, are in stratigraphic order but have very large uncertainties. The radiocarbon chronology at BDR-ST does not seem to give reliable information about the age of the sediments. The ${ }^{14} \mathrm{C}$ age (Beta83686 - AD435 \pm 60 ) on an endolithic shell of a tsunami boulder is much older than AD1755, so the bivalve died long before the tsunami. The ${ }^{14} \mathrm{C}$ ages from Dawson et al. (1995) for the units C1 (Beta-68853 - AD120 \pm 60 ) and C2 (Beta-68854 $\mathrm{AD} 840 \pm 60$ ) are not in stratigraphic order and give only a rough age estimate for the sediments accumulated prior to the tsunami.

In the BDR-NT trench (Fig. 3) the OSL ages for unit B (062253 $\mathrm{AD} 1699 \pm 23,062256-\mathrm{AD} 1677 \pm 26,062257-\mathrm{AD} 1648 \pm 21$, 062258 - AD1633 \pm 23 ) are again very reproducible but also overestimate the expected age of the tsunami, although to a lesser degree ( $~ 80$ years) than at BDR-ST. The results obtained from unit A $(062254-\mathrm{AD} 1796 \pm 12,062255-\mathrm{AD} 1819 \pm 30)$ and unit $\mathrm{C} 1$ $(062251-\mathrm{AD} 1453 \pm 36,062252$ - AD1408 \pm 48$)$ are stratigraphically consistent and bracket the expected age. The result most consistent with the expected age was obtained from the base of unit $A$ in the northern trench $(062254-A D 1796 \pm 12)$. The radiocarbon chronology is complex in the BDR-NT trench. From the same stratigraphic level in unit $\mathrm{C} 1$, the ${ }^{14} \mathrm{C}$ date on a charcoal fragment agrees well with our OSL age, but the ${ }^{14} \mathrm{C}$ ages obtained from a whole shell, and from a silty matrix, are probably overestimates. Two ${ }^{14} \mathrm{C}$ ages from unit C2 given by Allen (2003) agree well with each other and fit into the stratigraphy; two others from levels bracketing the tsunami layer are overestimates.

At Martinhal, our OSL ages are in stratigraphic order (Fig. 4), but again the ages obtained from sand and gravel layers expected to be deposited by the 1755 tsunami are overestimates (by $\sim 230$ years, excluding the bottom-most sample for which the overestimate is even larger, $\sim 1200$ years). From to historical reports, the 1755 flooding in Martinhal deposited boulders and a thick sand layer. We therefore expect that the 1755 deposits should be represented by, entirely or in part, the $\mathrm{L}$ and $\mathrm{M}$ layers. The ages reported by Kortekaas and Dawson (2007) for the same sand unit (M) in a trench close by $(1204 \pm 2008$ BC and AD1921 \pm 45 ; Fig. 4) are not useful (imprecise and no consistency at all with our ages nor the expected age) and are thus not discussed any further.

It is clear that at all three locations the age of the tsunami layer is overestimated by the OSL results. This may be because large aliquots average both well-bleached and incompletely-bleached grains. This is investigated in the next section. However, it is important here to emphasise that, with one exception, the overestimates are all in the range $50-250$ years. Such inaccuracies become increasingly unimportant as the age of the deposit increases. From our data, OSL ages from sediments deposited by tsunamis from the mid/early Holocene (or older) are unlikely to be significantly affected by incomplete bleaching.

\section{Small aliquot dose distributions}

In principle it is possible that at least part of the overestimation of the age of the tsunami sediments can be attributed to the use of large aliquots up of several thousand grains. Large aliquots may include both grains recording the dose in the material picked up from the beach during the tsunami run-up and other grains also from this material, but which were then exposed to light during the extreme coastal flood. The apparent dose recorded by such mixed 


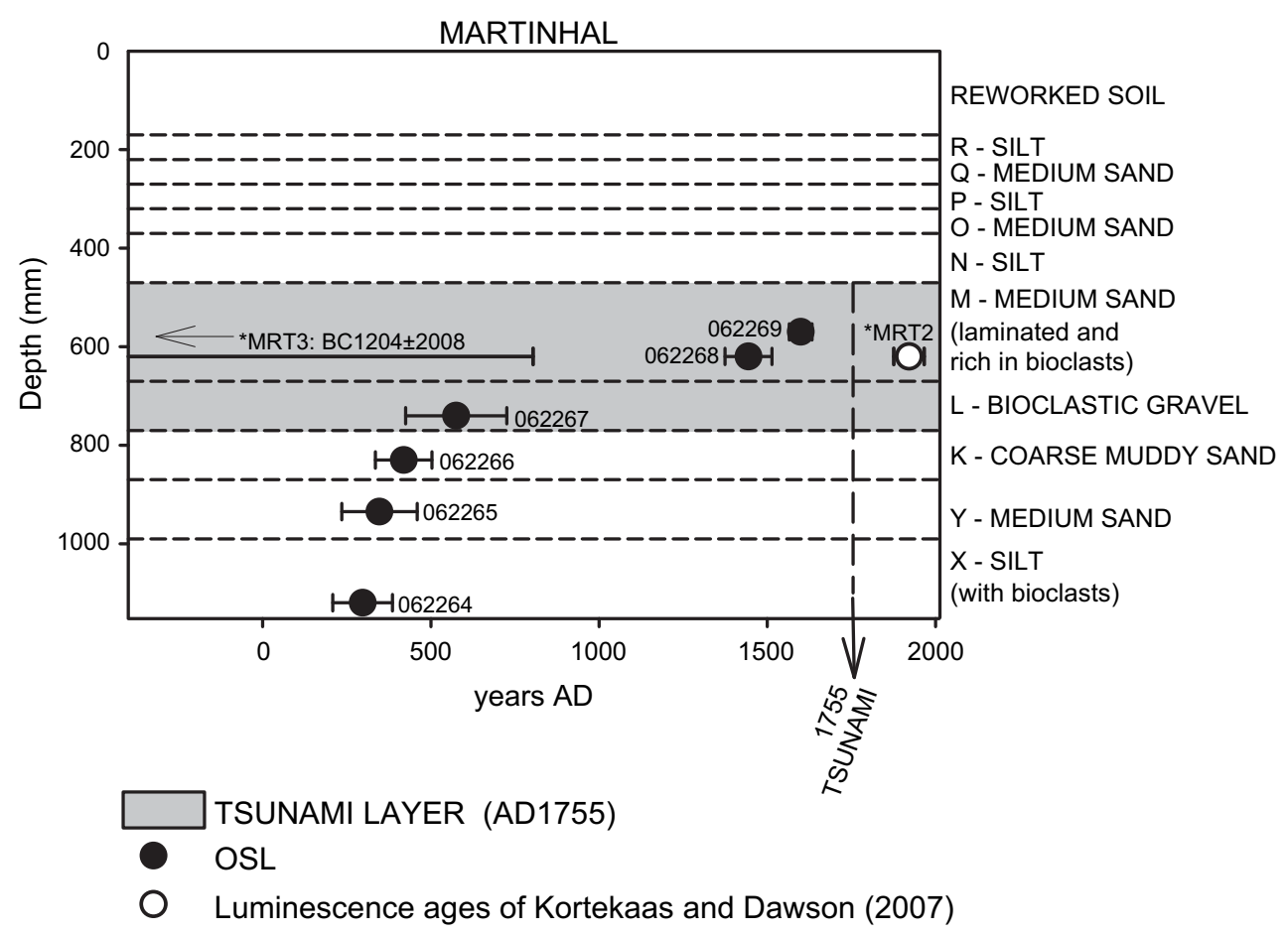

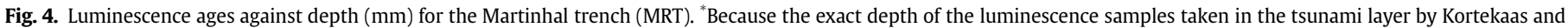
Dawson can not be reconstructed in our stratigraphy their results are plotted in the middle of tsunami layer.

populations will average these two dose distributions, and give a result lying somewhere between the age of the tsunami event, and that of the previous deposition recorded by the source material picked up on the beach and in the offshore shallow water. Analyses of dose distribution from small aliquot made up of $<100$ grains could perhaps allow the identification and quantification of the bleached population. In order to test this, we have measured small $(2 \mathrm{~mm})$ aliquot dose distributions from three samples collected from the tsunami layer at the different sites (062260 from BDR-ST; 062256 from BDR-NT; 062269 from MRT). Our small aliquots were checked under a microscope to confirm that they were made up of no more than a few tens of grains. The dose results are presented as histogram and radial plots in Fig. S4 (the acceptance criteria are discussed in the figure caption).

From Fig. S4 it is clear that at least for two samples (062256 [BDR-NT; mean overestimate $~ 80$ years] and 062269 [MRT; mean overestimate $\sim 230$ years]) the expected age (straight lines in radial plots) is recorded in the lower edge of the distributions. Interestingly, application of the 4-parameter minimum-age model of Galbraith et al. (1999) to these distributions yields ages that are completely consistent with the expected age of 250 years (age MAM- $_{4}$ $062256=0.245 \pm 0.016 \mathrm{ka} ;$ age $\left._{\text {MAM }-4} 062269=0.276 \pm 0.016 \mathrm{ka}\right)$. However, for sample 062260 (BDR-ST; mean overestimate 200 years) not a single result is consistent with the expected age. It is well-known that surficial (top few $\mathrm{cm}$ ) beach sediments are very well-bleached, with samples yielding luminescence ages consistent with zero (see review Madsen and Murray, 2009). For the BDR-NT and MRT samples, given the fact that we obtain the right answer using the minimum-age model, it is possible that some bleaching has occurred during transport and deposition or that some modern beach sediment was incorporated in the tsunami sediment mixture. For the BDR-ST sample it is very unlikely that any significant bleaching occurred during tsunami transport after the material was picked up or that any modern beach was included in the sample. In any case, the distributions suggest that for all three samples, the tsunami scraped the beach and shallow marine deposits to such a depth that the transported sediment was mainly made up of material of finite age (a few tens to few hundred years old).

\section{Discussion}

In the BDR-NT trench, OSL overestimates the expected tsunami age by 60-120 years; this is of the same order as that observed from sediments deposited on the east coast of India by the 2004 Sumatra tsunami (Murari et al., 2007). The overestimation at BDR-ST $(300 \mathrm{~m}$ inland) is larger (180 - 230 years) than that from BDR-NT (600 m inland). At Martinhal ( $100 \mathrm{~m}$ inland), an overestimation (at least $\sim 230$ years) larger to that at BDR-ST is observed. This could be because the tsunami-transported sands deposited close to the estuary mouth contain a larger contribution from deeper sediments of finite age eroded by funnelling of the tsunami at the embayment entrance. However, most of the tsunami-laid sands should have been eroded from the shallow tidal and sub-tidal shore, and these should be common to both sites. It may also be that the shallower water depth $600 \mathrm{~m}$ inland allowed more opportunity for bleaching.

In the small aliquot dose distributions, sample 062260 from BDR-ST (300 m inland) does not have any result consistent with the expected dose whereas for the other two samples the low dose end of the distribution contains the expected dose. In our opinion, this places more weight on the interpretation that no significant bleaching occurred during transport and deposition but that the tsunami picked up and deposited a mixture of modern beach sand and older material at BDR-NT and MRT but that the tsunami layer at BDR-ST contains only older material.

Based on the large aliquot results presented in our study, we suggest that any future OSL sampling strategy should include both the probable tsunamigenic sand layer and also the low-energy deposits immediately above and below. At site BDR-NT, the ages of the sediments above and below the tsunami layer bracket the 
expected age. One should also consider sampling at least two different distances inland from the coast. Our study indicates that the section located more inland (BDR-NT) provided ages closer to the tsunami event. This could be the result of a smaller contribution from older underlying sediments or more opportunity for bleaching with increased inland transport distance.

In our study, we collected OSL samples from the middle of the tsunami layer. Especially in areas close to human occupation and agricultural activity, we think it is likely that the upper few $\mathrm{cm}$ of the deposit will have been bioturbated and thus bleached further, after deposition but before later burial by fluvial flood sediments. This could be investigated with a more detailed sampling strategy in which thinner samples $(1-2 \mathrm{~cm})$ are taken in a vertical transect through the tsunami layer and the overlying sediment.

\section{Conclusions}

In this study we have revisited the Boca do Rio and Martinhal sites, on the Algarve coast in Portugal. Both sites contain a sedimentary record of the large 1755 tsunami event. An extensive sampling strategy, with multiple OSL samples in the tsunamigenic sediments and the over- and underlying deposits was used. Standard large aliquot quartz SAR-OSL dating was employed and extensive laboratory testing shows that the coarse quartz grains from these deposits behave well in our SAR protocol. Our OSL ages are remarkably reproducible within the same site but overestimate the high-energy flooding event (AD1755) by up to 120 years $(+50 \%)$ at the BDR-NT trench ( $600 \mathrm{~m}$ inland), and by up to 230 years $(+90 \%)$ at the BDR-ST (300 $\mathrm{m}$ inland) and the Martinhal trench; the latter is only $100 \mathrm{~m}$ inland and close to a sand barrier. The age overestimation of the tsunami-laid sands is presumably due to fast erosion and deposition of older sediments that have been carried from the near offshore, without significant bleaching of the sediment during transport. Small ( $2 \mathrm{~mm}$ ) aliquot dose distributions for three samples do not indicate any convincing evidence for significant bleaching after the material has been picked up by the tsunami. Nevertheless, for two out of the three distributions the lower dose edge seems to yield the correct age when the minimum-age model is applied, which, in our opinion, suggests that for those two samples some modern beach sand was also picked up by the tsunami. The closest age to the event was obtained from alluvial silts that directly cover the tsunami bed. We conclude that using standard large aliquot quartz SAR-OSL dating of the sediments deposited by the 1755 tsunami layers yields age overestimations of the order of a few tens to few hundred years; such offsets will, of course, be negligible when dating tsunami layers of a thousand years or older.

\section{Acknowledgements}

This work has been supported by project CTE-GEX/65948/2006, approved by the Fundação para a Ciência e a Tecnologia and cofounded by the FEDER, but also by the EU project 037110-GOCE2006. Support from the Nordic Centre of Excellence programme of the Joint Committee of the Nordic Natural Science Research Councils is gratefully acknowledged. Research was also supported by the Marine and Environmental Research Centre - Univ. Coimbra, Centro de Geofísica - Univ. Évora, Centro de Geologia - Univ. Lisboa and Risø DTU. We warmly thank Sébastien Huot for carrying out the minimum-age model analyses. We thank A.K. Singhvi, Barbara Mauz and an anonymous referee for several helpful comments and improvements.

\section{Appendix. Supplementary material}

Supplementary data associated with this article can be found, in the online version, at doi:10.1016/j.quageo.2009.09.004.

Editorial Handling by: R. Grün

\section{References}

Aitken, M.J., 1985. Thermoluminescence Dating. Academic Press, London. p.359.

Allen, H.D., 2003. A transient coastal wetland: from estuarine to supratidal conditions in less than 2000 years - Boca do Rio, Algarve, Portugal. Land Degradation \& Development 14, 265-283.

Andrade, C., Hindson, R., Freitas, C., Dawson, A., 1994. Sedimentary evidence of tsunami flooding in Algarve lowlands. In: Carvalho, G., Gomes, F. (Eds.), Littoral '94, Proc. 2nd Internat. Sympos. Eurocoast, Lisboa, pp. 1035-1036.

Banerjee, D., Murray, A.S., Foster, I.D.L., 2001. Scilly Isles, UK: optical dating of a possible tsunami deposit from the 1755 Lisbon earthquake. Quaternary Science Reviews 20, 715-718.

Bryant, E.A., Young, R., Price, D.M., 1996. Tsunami as a major control on coastal evolution, Southeastern Australia. Journal of Coastal Research 12, 831-840.

Baptista, M., Miranda, P., Miranda, J., Mendes-Victor, L., 1998a. Constraints of the source of the 1755 Lisbon tsunami inferred from numerical modelling of historical data on the source of the 1755 Lisbon tsunami. Journal of Geodynamics 25, 159-174.

Baptista, M., Heitor, S., Miranda, J., Mendes-Victor, L., 1998b. The 1755 Lisbon tsunami; evaluation of the tsunami parameters. Journal of Geodynamics 25, 143-157.

Bøtter-Jensen, L., Andersen, C.E., Duller, G.A.T., Murray, A.S., 2003. Developments in radiation, stimulation and observation facilities in luminescence measurements. Radiation Measurements 37, 535-541.

Dawson, A.G., 1994. Geomorphological effects of tsunami run-up and backwash. Geomorphology 10, 83-94.

Dawson, A.G., Hindson, R., Andrade, C., Freitas, C., Parish, R., Bateman, M., 1995. Tsunami sedimentation associated with the Lisbon earthquake of November $1 \mathrm{st}$ 1755 AD: Boca do Rio, Algarve-Portugal. The Holocene 5, 209-215.

Duller, G.A.T., 2003. Distinguishing quartz and feldspar in single grain luminescence measurements. Radiation Measurements 37, 161-165.

Galbraith, R.F. Roberts, R.G. Laslett, G.M. Yoshida, H., Olley, J.M., 1999. Optical dating of single and multiple grains of quartz from Jinmium rock shelter, northern Australia: Part I, experimental design and statistical models. Archaeometry 41, 339-364.

Hindson, R., Andrade, C., 1999. Sedimentation and hydrodynamic processes associated with the tsunami generated by the 1755 Lisbon earthquake. Quaternary International 56, 27-38.

Hindson, R., Andrade, C., Parish, R., 1999. A microfaunal and sedimentary record of environmental change within the late Holocene sediments of Boca do Rio (Algarve, Portugal). Geologie en Mijnbouw 77, 311-321.

Huntley, D.J., Clague, J.J., 1996. Optical dating of tsunami-laid sands. Quaternary Research 46, 127-140.

Kortekaas, S., Dawson, A., 2007. Distinguishing tsunami and storm deposits: an example from Martinhal, SW Portugal. Sedimentary Geology 200, 208-221.

Madsen, A.T., Murray, A.S., 2009. Optically stimulated luminescence dating of young sediments: a review. Geomorphology 109, 3-16.

Morales, J.A., Borrego, J., San Miguel, E.G., López-González, N., Carro, B., 2008. Sedimentary record of recent tsunamis in the Huelva estuary (southwestern Spain). Quaternary Science Reviews 27, 734-746.

Murari, M.K., Achyuthan, H., Singhvi, A.K., 2007. Luminescence studies on the sediments laid down by the December 2004 tsunami event: prospects for the dating of paleo tsunamis and for the estimation of sediment fluxes. Current Science 92 (3), 367-371.

Murray, A.S., Marten, R., Johnston, A., Martin, P., 1987. Analysis for naturally occurring radionuclides at environmental concentrations by gammaspectrometry. Journal of Radioanalytical and Nuclear Chemistry 115, 263-288.

Murray, A., Wintle, A., 2000. Luminescence dating of quartz using an improved single-aliquot regenerative-dose protocol. Measurements 32, 57-73.

Murray, A.S., Wintle, A.G., 2003. The single aliquot regeneration dose protocol: potential for improvements in reliability. Radiation Measurements 37, 377-381.

Ollerhead, J., Huntley, D.J., Nelson, A.R., Kelsey, H.M., 2001. Optical dating of tsunami-laid sand from an Oregon coastal lake. Quaternary Science Reviews 20, 1915-1926.

Prescott, J.R., Hutton, J.T., 1994. Cosmic ray contributions to dose rates for luminescence and ESR dating: large depths and long-term variations. Radiation Measurements 23, 497-500.

Silva, C., Hindson, R., Andrade, C., 1996. Bioerosion evidence of extreme marine flooding of Algarve region (Southern Portugal) associated with the tsunami of the AD 1755 Lisbon earthquake. Taphonomic and paleoecological analyses. Proceedings, Taphos'96-II Reunion de tafonomia e fosilizacion, Zaragoza, 371-378. 